\section{APPLYING TRANSCRIPT 1.23 IN IMPROVING THE STUDENTS' WEAK FORMS AND CONNECTED SPEECH}

\author{
Azman \\ Teacher Training and Education Faculty \\ Tanjungpura University, Pontianak \\ azman.sholihin@yahoo.com
}

Effectiveness, Transcript 1.23, Connected Speech

\begin{abstract}
This true experimental research is mainly aimed at investigating the effectiveness of using Computer-assisted Pronunciation Teaching (CAPT) application software Transcript 1.23 in teaching English pronunciation of weak forms and connected speech. The data used to measure the effectiveness of the application of CAPT software in the treatment is collected from participants' oral performance in the form of voice records. The research involved the Government Islamic Senior High School 2 Pontianak. The pre-test and pos-test data from the participants is analysed and compared to measure the effect of the given treatment. The result of the research demonstrates a strong effect of the application of the software to improve the quality of the participants' pronunciation of weak forms and connected speech. The effectiveness the application of the software is categorised as strong according to the criteria developed by Cohen.
\end{abstract}

Keywords: Effectiveness, CAPT, Transcript 1.23, Weak Pronunciation, Connected Speech

\title{
INTRODUCTION
}

Pronunciation is an important aspect of English speaking competency that teachers need to teach to their students. Teaching pronunciation is important because correct pronunciation determines the accomplishment of communication process. Learners with poor pronunciation will cause problem to be understood, even though they are good at grammar and rich in vocabulary. Gilakjani (2012, p.96) claims that learners with good English pronunciation are likely to be understood even if they make errors in other areas. Meanwhile, learners with bad pronunciation will not be understood even if their grammar is perfect. It can be concluded that speakers whose pronunciation is listener-friendly are able to lead a successful conversation even with their grammatical mistakes better than speakers whose grammar obeys all the rules.

Unfortunately, teaching pronunciation is paid less attention by teachers in English language classrooms around the world. This is because the subject has been drilled to death with too few results from too much effort. Kelly cited in Seyedabadi

SPECTRAL

Jurnal Ilmiah STBA Vol.6 No.2

Juni 2020 ISSN 0216-3381 
Effectiveness,

Transcript

1.23 ,

Connected

Speech

(2015) states that pronunciation teaching has been an area of neglect compared to other language skills and sub-skills. In addition, Tennant (2007) claims that pronunciation is one area of teaching which is often neglected. Underhill and Griffiths cited in Tejeda (2014) have pointed out that teaching pronunciation has been neglected by teachers. This

069 is evident in the way that pronunciation is treated in most course books. They concur that when pronunciation is studied in the classroom, it tends to deal only with specific pronunciation problems that happen in the precise moment of student's performance. The reasons that teachers neglect the teaching of pronunciation might be due to the fact that speaking is excluded in the Senior High School final examination. Secondly, handbooks for Senior High School students discussing sentence-level pronunciation are unavailable. Thirdly, teachers' theoretical knowledge might be limited in this field. McDonald cited in Gilbert (2010) surveyed teachers' reasons to be reluctant to teach pronunciation because the absence of pronunciation in curricula, a lack of suitable teaching and learning materials of a high quality and an absence of a skills and assessment framework with which to map student ability and progress in this area.

At least two important reasons underground the teaching of weak forms and connected speech. First of all, weak forms and connected speech represent a very real part of the English language. Indeed, it may be part of all living languages. Secondly, teaching connected speech has facilitative roles in improving EFL students' listening comprehension skill. Therefore, students need to be exposed to and taught about weak forms and connected speech. Students also need to be able to adjust their styles and registers in using language, and the ability to understand and use connected speech is essential for making such adjustments.

Previous studies by Derwing \& Munro (2005), Gilner (2008), and Baker \& Murphy (2011) (cited in Seyedabadi et.al. (2015) demonstrates the ignorance of pronunciation teaching within the English as a foreign/second language (EFL/ESL) classroom context, teacher training programs, course materials, and applied linguistics study. The teaching of pronunciation would rather be given spontaneously only when students pronounce words incorrectly than being planned seriously. Pronunciation, which has been long on the periphery of applied linguistics research and pedagogy, continues to grow in importance because of its central roles in speech recognition speech perception, and speaker identity (Levi, 2008). 
During the researcher's teaching activity, the students shows their problem in applying weak pronunciation forms and connected speech in their oral performance. Most students apparently recognise only the words' strong pronunciation form. This fact is reasonable since most students depend themselves only on dictionaries in learning word pronunciation. It is undeniable that students can successfully acquire individual word Effectiveness, Transcript

1.23 , Connected Speech pronunciation. Another pronunciation problem that the researcher detects in his teaching activity in the classroom is that students keep pronouncing separately each word in a series of syntactical construction. Only few of the students in his teaching experience use the features of connected appropriately when speaking. In fact, such pronunciation hardly occurs in the smooth flow of natural speaking.

Based on the researcher's teaching experience in his classroom, the students hardly ever weaken the pronunciation of function words and strengthen the content words to focus the message of the sentence. They also rarely link word sounds of the neighbouring words in a construction. The students performed such a pronunciation because they might be unaware of the presence of such connected speech in spoken English. This case happens to the students because their teachers might have never taught them about such features of connected speech in natural spoken English. In the preobservation stage, the researcher finds that the students also pronounce a series of numbers one by one. They pronounce telephone number, for example 38608482, as / $\theta$ ri:

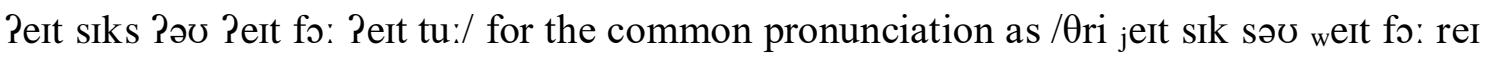
tu:/. Consequently, the students' pronunciation sounds peculiar by a staccato effect caused by their disconnected pronunciation. Such a pronunciation problem is by far identified when the students are performing a speaking activity in the classroom.

The students' failure in using weak forms and connected speech might be the result of the teacher's ignorance to teach the concerned phonological aspects to them. Therefore, the students have no knowledge about weak form and connected speech in natural spoken language. It is noteworthy that the failure to introduce the pronunciation feature of spoken English can cause the student to fail in speaking English naturally to fluent or native speakers. Besides, the students will also potentially fail in comprehending the speech of native and fluent speakers of English.

To solve the problem related to the students' pronunciation of weak form and connected speech, creative and innovative techniques of teaching and learning pronunciation need 
Effectiveness, Transcript

1.23 , Connected Speech

developing continuously. Not only should the new teaching techniques effectively facilitate the teaching task for the teacher, but they should also be interesting to the students. Therefore, both the teacher and the students find the classroom activity motivating. More importantly, the technique should be effective to improve significantly

the students' pronunciation of weak form and connected speech.

Various types of computer application software to facilitate teachers in the teaching of pronunciation have been developed. The rapid growth of computer technology in this modern era has caught the attention of language teachers for the pronunciation teaching. With the influence of computer technology on language education, relationship between language ability and computer use have gained more attention during the last decade. Computer-assisted Pronunciation Teaching (CAPT) is perceived as a technique to language teaching and learning in which the computer is used as an aid to present, reinforce, and assess the material to teach.

Result findings conducted by Neri, Mich, Gerosa and Giuliani (2008) show that pronunciation quality of isolated words improved significantly for both groups of subjects, and both groups significantly improved in pronunciation quality of words that were considered particularly difficult to pronounce. Based on this factual data, the improvement of students' pronunciation of sentence-level pronunciation needs investigating. The use of computer software might improve the students' competence in acquiring the weak forms and connected speech processes.

Felix cited in AbuSeileek (2007) also reports that computer-based pronunciation teaching is one of the areas that receive less attention from the published research studies. Nevertheless, Stockwell cited in AbuSeileek (2007) claims that there has been a slight increase in interest in recent years. According to Lee cited in Lai \& Kristonis (2006) the increase of interest in using CALL in second language instruction is based on the fact that computer learning programs can (a) prove practices for students through the experiential learning, (b) offer students more the learning motivation, (c) enhance student achievement, (d) increase authentic materials for study, (e) encourage greater interaction between teachers and students and students and peers, (f) emphasize the individual needs, (g) regard independence from a single source of information, and (h) enlarge global understanding. With enormous advancement in information technology (IT), computer 
application softwares have been used in the field of language learning process which is known as Computer-assisted Language Learning (CALL).

Effectiveness, Transcript

1.23,

There are various English phonetic transcription applications available such as: 1) English Phonetic Transcription published at upodn.com, 2) Phonetizer by Alexei Vinidictov, 3) English Phonetic Transcription Converter by Timur Baytukalov, 4) Wikspeak by Marcos Daniel Martinez, and 5) PhoTransEdit ${ }^{\circledR}$ by Students of English from Getafé University Spain, 6) Transcript1.23 by Ho Nguyen Van Khoa. The pronunciation teaching software comes to market with their inferiority and superiority either as shareware or freeware. The researcher offers solution to the teacher to solve the problem of introducing the sentence-level pronunciation that the students experience. The researcher introduces CAPT software called Transcript1.23 to solve the concerned problem. The software is recommended because it provides the teacher with sentencelevel pronunciation encompassing features of authentic spoken language such as weak forms and connected speech. Nevertheless, the effectiveness of applying the software still needs systematic investigating to find the accurate data concerning the fact in the field.

This research is significant because the emphasis of language teaching nowadays has been on the communicative competence that relies greatly on the acquisition of natural pronunciation competence. Celce-Murcia (2008) claims that communicative approach is currently dominant in language teaching. Thus, the primary purpose of language teaching is for successful communication. This focus of language teaching emphasizes the urgency to the teaching of comprehensible pronunciation. If the students fail in pronunciation, they may encounter communication difficulty regardless their excellent and extensive acquisition of grammar and vocabulary. It means that the English teaching trend has moved recently to emphasize spoken language functions and communicative competence.

This research is also important at least in three issues. Firstly, this research detects the participants' prior competence on the pronunciation of weak form in pre-test before a treatment is given. Hence, it can help teachers to anticipate the problem that the students encounter. Secondly, this research measures the effectiveness of the treatment using the CAPT software Transcript 1.23. Thirdly, this research discovers the effectiveness of applying CAPT software Transcript1.23 in the teaching and learning process to improve the students' pronunciation of weak forms and connected speech.
Connected Speech

072 
Effectiveness,

Transcript

1.23 ,

Connected

Speech

\section{METHODS}

This research is a true experimental study with pre-test, treatment and post-test design. The selection of the subjects applies random sampling. The true experimental

073 research with random sampling is applied in this research because the subjects are classified into classrooms without considering their English competence. There is no sorting of intelligence among the subjects before seating them into studying units. The subjects of this research are the State Islamic Senior High School (MAN 2) Pontianak grade XI students who are learning narrative text at the time the research is being conducted. The subjects are divided into an Experimental Group (EG) and a Control Group (CG). The participants are assigned to tell a narrative story and record their voice. The participants' voice records are then transcribed into written text. After the pre-test data is collected, a treatment is given to the EG. In the treatment process, the subjects are taught using CAPT software Transcript1.23 as the teaching media. Hence, the EG students have the chance to observe the phonetic script produced by the CAPT software on the screen.

In the same time, the CG is taught conventionally in a sense that the researcher plays his role as the model in reading the text. The researcher read the text by applying the sentence-level pronunciation as described in the manuscript written in International Phonetic Alphabet (IPA). A pre-test is given to both experimental and control group to identify the subjects' initial skill. A treatment is only be given to the experimental group. After a treatment is conducted, both groups are tested again by asking the subjects to read again the same monologue as the one that they read in the pre-test activity. All subjects of both experimental and control groups of this research are assigned to record their voice while telling the story prepared by the researcher. The recording process is done at home to avoid disturbing noises and to keep the participant confident. The unconfident subjects feel free to express themselves in telling the story. Another advantage of recording their voice at home is that the subjects can repeat the recording process when they feel unsatisfied with their previous result. The subjects may tell the story by simply reading the text.

The researcher collected data from the subjects by assigning them to tell the story and record it. The subjects may repeat their pronunciation to correct their previous pronunciation. Thus, the second pronunciation uttered by the subjects is considered as the 
Effectiveness, Transcript

correct pronunciation. The researcher transcribes the subjects' spoken story and then transcribes it in International Phonetic Alphabet (IPA). The pronunciation that the subjects find unfamiliar is given in IPA. The researcher also exemplifies the pronunciation of the unfamiliar words to the subjects. The researcher only pronounces the word individually when the subject asks him to exemplify the pronunciation. The researcher avoids informing the subject about the proper pronunciation of the words in construction (sentence-level construction) in pre-treatment test. The introduction of sentence level pronunciation is only given in the treatment to both groups.

The specially designed narrative text given to the subject consists of 100 possible sound linking. Therefore, the subjects' individual score is the total correct linking pronunciation that the subjects produce. Every correct sound linking that subjects pronounce deserves for 1 (one) score point. In conclusion, subject's individual score for linking pronunciation is the total score of correct sound linking that the subjects make.

The subject was assigned individually to tell the story by reading the text which had been prepared previously. The text given to the subject was a monologue narrative text. The text is entitled 'The crocodiles and the mouse deer'. The story was chosen because the subjects have been familiar with the plot of the story. Therefore, the subjects had no burden to comprehend a new unfamiliar narrative in the story telling process. The text is in the form of a fable narrative text containing 80 function words that are naturally pronounced in weak forms by native or fluent speakers. The text also contains 100 potential linking sounds that comprise consonant to vowel and vowel to vowel linking.

The mean difference of pre-test and post-test scores of both EG and CG is observed. The score difference between pre-test and post-test of EG and CG reflects the category of effectiveness of the given treatment to the EG. Afterwards, the level of the treatment is classified based on the rubric developed by Cohen (2007) and the data is interpreted based on a rubric developed by Coe (2002).

\section{FINDINGS AND DISCUSSION}

\section{Findings}

The data presented below exhibits the subjects' achievement on the aspects of pronunciation being investigated. The data encompasses the pre-test, post-test scores, the score difference and the squared score difference of the subjects. Findings are obtained
1.23 ,

Connected

Speech 
Effectiveness,

Transcript

1.23 ,

Connected

Speech after manipulating the required data. The findings of the investigated issues in this research are described below.

\section{CAPT application software Transcript1.23 is effective to improve the students' weak}

\section{forms}

Based on the obtained data, the use of CAPT software Transcript1.23 improves each subject's score. The subjects' individual scores demonstrate improvement in using weak forms and so do the subjects' mean score. The mean score difference between the pre-test and post-test indicates the improvement of subjects' competence in pronouncing weak forms of function words. The collected data demonstrates the subjects' variety in recognising the weak forms before and after a experimental treatment. The students' pretest score in using the weak forms is lower than that of the post-test. The effectiveness of using CAPT software Transcript1.23 to improve the students' weak forms is described in the table below.

Table 1

Subject's Score of Weak Forms Experimental Group

\begin{tabular}{|c|c|c|c|c|c|c|c|}
\hline \multirow{2}{*}{ No } & \multirow{2}{*}{$\begin{array}{l}\text { Subjects' } \\
\text { Code }\end{array}$} & \multicolumn{2}{|c|}{ Pretest } & \multicolumn{2}{|c|}{ Post-test } & \multirow{2}{*}{$\begin{array}{c}\text { D } \\
\text { Post-test } \\
\text { - Pretest }\end{array}$} & \multirow{2}{*}{$\mathrm{D}^{2}$} \\
\hline & & Score & Value & Score & Value & & \\
\hline 1 & S-1 & 35 & 43.75 & 48 & 60.00 & 16.25 & 264.06 \\
\hline 2 & $S-2$ & 34 & 42.50 & 59 & 73.75 & 31.25 & 976.56 \\
\hline 3 & $S-3$ & 34 & 42.50 & 41 & 51.25 & 8.75 & 76.56 \\
\hline 4 & S-4 & 34 & 42.50 & 56 & 70.00 & 27.50 & 756.25 \\
\hline 5 & S-5 & 31 & 38.75 & 64 & 80.00 & 41.25 & 1701.56 \\
\hline 6 & S-6 & 31 & 38.75 & 62 & 77.50 & 38.75 & 1501.56 \\
\hline 7 & S-7 & 39 & 48.75 & 64 & 80.00 & 31.25 & 976.56 \\
\hline 8 & S-8 & 36 & 45.00 & 64 & 80.00 & 35.00 & 1225.00 \\
\hline 9 & S-9 & 34 & 42.50 & 64 & 80.00 & 37.50 & 1406.25 \\
\hline 10 & S-10 & 36 & 45.00 & 62 & 77.50 & 32.50 & 1056.25 \\
\hline 11 & S-11 & 32 & 40.00 & 72 & 90.00 & 50.00 & 2500.00 \\
\hline 12 & S-12 & 33 & 41.25 & 57 & 71.25 & 30.00 & 900.00 \\
\hline 13 & S-13 & 37 & 46.25 & 68 & 85.00 & 38.75 & 1501.56 \\
\hline 14 & S-14 & 30 & 37.50 & 68 & 85.00 & 47.50 & 2256.25 \\
\hline 15 & S-15 & 35 & 43.75 & 57 & 71.25 & 27.50 & 756.25 \\
\hline 16 & S-16 & 37 & 46.25 & 66 & 82.50 & 36.25 & 1314.06 \\
\hline 17 & S-17 & 35 & 43.75 & 59 & 73.75 & 30.00 & 900.00 \\
\hline 18 & S-18 & 33 & 41.25 & 64 & 80.00 & 38.75 & 1501.56 \\
\hline
\end{tabular}


Effectiveness,

\begin{tabular}{|c|c|c|c|c|c|c|c|}
\hline \multirow[b]{2}{*}{ No } & \multirow{2}{*}{$\begin{array}{c}\text { Subjects' } \\
\text { Code }\end{array}$} & \multicolumn{2}{|c|}{ Pretest } & \multicolumn{2}{|c|}{ Post-test } & \multirow{2}{*}{$\begin{array}{c}\text { D } \\
\text { Post-test } \\
\text { - Pretest }\end{array}$} & \multirow[b]{2}{*}{$D^{2}$} \\
\hline & & Score & Value & Score & Value & & \\
\hline 19 & S-19 & 32 & 40.00 & 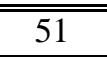 & 63.75 & 23.75 & $\overline{564.06}$ \\
\hline \multirow[t]{2}{*}{20} & S-20 & 36 & 45.00 & 51 & 63.75 & 18.75 & 351.56 \\
\hline & & & $\bar{X}=42.75$ & & $\bar{X}=74.81$ & 641 & 22486 \\
\hline
\end{tabular}

Transcript

1.23,

Connected

Speech

The Mean Difference Score of Experimental Group $\left(\mathrm{MD}_{\mathrm{e}}\right)$ of Weak Pronunciation is calculated by the following equation: $M D=M_{2}-M_{1}$

$$
\begin{aligned}
& \mathrm{MD}_{\mathrm{e}}=74.81-42.75 \\
& \mathrm{MD}_{\mathrm{e}}=32.06
\end{aligned}
$$

A Standard Deviation (SD) subjects' scores is needed to measure the effectiveness of the experimental treatment. SD is a measurement of the dispersion of a set of data from its mean. The more spread apart the data, the higher the deviation.

Therefore, the SD of the weak pronunciation performed by the Experimental Group (EG) is calculated by applying the equation below:

$$
\begin{aligned}
& \mathrm{SD}_{\mathrm{e}}=\sqrt{\frac{22486-\frac{(641)^{2}}{20}}{20-1}} \\
& \mathrm{SD}_{\mathrm{e}}=\sqrt{\frac{22486-20544}{19}} \\
& \mathrm{SD}_{\mathrm{e}}=\sqrt{\frac{1942}{19}}=\sqrt{102} \\
& \mathrm{SD}_{\mathrm{e}}=10
\end{aligned}
$$

The data of pretest and post-test score of using CAPT software Transcript1.23 to improve the students' weak forms is described in the table below. The table also illustrates the mean score difference of pre-test and post-test between the EG and CG. 
Effectiveness,

Transcript

1.23 ,

Connected

Speech

077

Table 2

Subject's Score of Weak Pronunciation of Control Group

\begin{tabular}{|c|c|c|c|c|c|c|c|}
\hline \multirow{2}{*}{ No } & \multirow{2}{*}{$\begin{array}{l}\text { Subjects } \\
\text { Code }\end{array}$} & \multicolumn{2}{|c|}{ Pretest } & \multicolumn{2}{|c|}{ Post-test } & \multirow{2}{*}{$\begin{array}{c}\text { D } \\
\text { Post-test } \\
\text { - Pretest }\end{array}$} & \multirow{2}{*}{$\mathbf{D}^{2}$} \\
\hline & & Score & Value & Score & Value & & \\
\hline 1 & S-1 & 35 & 43.75 & 53 & 66.25 & 22.50 & 506.25 \\
\hline 2 & S-2 & 33 & 41.25 & 42 & 52.50 & 11.25 & 126.56 \\
\hline 3 & S-3 & 34 & 42.50 & 44 & 55.00 & 12.50 & 156.25 \\
\hline 4 & S-4 & 34 & 42.50 & 45 & 56.25 & 13.75 & 189.06 \\
\hline 5 & S-5 & 31 & 38.75 & 36 & 45.00 & 6.25 & 39.06 \\
\hline 6 & S-6 & 34 & 42.50 & 39 & 48.75 & 6.25 & 39.06 \\
\hline 7 & S-7 & 30 & 37.50 & 55 & 68.75 & 31.25 & 976.56 \\
\hline 8 & S-8 & 36 & 45.00 & 49 & 61.25 & 16.25 & 264.06 \\
\hline 9 & S-9 & 34 & 42.50 & 49 & 61.25 & 18.75 & 351.56 \\
\hline 10 & S-10 & 36 & 45.00 & 53 & 66.25 & 21.25 & 451.56 \\
\hline 11 & S-11 & 32 & 40.00 & 41 & 51.25 & 11.25 & 126.56 \\
\hline 12 & S-12 & 33 & 41.25 & 41 & 51.25 & 10.00 & 100.00 \\
\hline 13 & S-13 & 34 & 42.50 & 59 & 73.75 & 31.25 & 976.56 \\
\hline 14 & S-14 & 34 & 42.50 & 40 & 50.00 & 7.50 & 56.25 \\
\hline 15 & S-15 & 35 & 43.75 & 41 & 51.25 & 7.50 & 56.25 \\
\hline 16 & S-16 & 36 & 45.00 & 50 & 62.50 & 17.50 & 306.25 \\
\hline 17 & S-17 & 33 & 41.25 & 45 & 56.25 & 15.00 & 225.00 \\
\hline 18 & S-18 & 38 & 47.50 & 39 & 48.75 & 1.25 & 1.56 \\
\hline 19 & S-19 & 32 & 40.00 & 42 & 52.50 & 12.50 & 156.25 \\
\hline \multirow[t]{2}{*}{20} & S-20 & 36 & 45.00 & 45 & 56.25 & 11.25 & 126.56 \\
\hline & & & $\begin{array}{c}\bar{X}= \\
42.50\end{array}$ & & $\begin{array}{l}\bar{X}= \\
56.75\end{array}$ & $\sum=285$ & $\begin{array}{l}\sum_{5231}= \\
\end{array}$ \\
\hline
\end{tabular}

$\mathrm{MD}=\mathrm{M}_{2}-\mathrm{M}_{1}$

$\mathrm{MD}_{\mathrm{c}}=56.75-42.50$

$\mathrm{MD}_{\mathrm{c}}=14.25$

The Standard Deviation (SD) of the weak pronunciation score performed by the

Control Group is calculated by applying the formula below:

$$
S_{c}=\sqrt{\frac{5231-\frac{(285)^{2}}{20}}{20-1}}
$$




$$
\begin{aligned}
& S_{c}=\sqrt{\frac{5231-4061.25}{19}} \\
& S_{c}=\sqrt{61.57} \\
& S_{c}=7.85
\end{aligned}
$$

Effectiveness, Transcript

1.23 ,

Connected Speech

Pooled Standard Deviation $\left(\mathrm{S}_{\mathrm{p}}\right)$ is quantified by applying the equation below:

$$
\begin{aligned}
& S_{p}=\frac{10+7.85}{2}=\frac{17.85}{2} \\
& S_{p}=8.92
\end{aligned}
$$

The Mean Score Difference of Control Group $\left(\mathrm{MD}_{\mathrm{c}}\right)$ is obtained by comparing the score difference between the pretest and post test score.

$$
\begin{aligned}
& \mathrm{MD}_{\mathrm{c}}=\mathrm{M}_{2}-\mathrm{M}_{1} \\
& \mathrm{MD}_{\mathrm{c}}=56.75-42.50 \\
& \mathrm{MD}_{\mathrm{c}}=14.25
\end{aligned}
$$

The Effect Size (d) of the treatment is calculated by applying the following equation:

$$
\begin{aligned}
& d=\frac{32.06-14.25}{8.92} \\
& d=\frac{17.81}{8.92} \\
& d=1.99
\end{aligned}
$$

Therefore, by referring the score $(\mathrm{d}=1.99)$ to the Effect Size criteria developed by Cohen, the size effect of the treatment to improve the weak form of function words is categorised "strong". This conclusion is made because the score of the effect size is bigger than one (1). Based on the score, it can be interpreted that as many as $97 \%$ of the CG are below the average person in the EG after the treatment was given

\section{CAPT application software Transcript 1.23 is Effective to improve the students' connected speech.}

CAPT software is used in the treatment given to the Experimental Group. The comparison between the pre-test and post-test scores determines the effectiveness of the use of the media, in this case Transcript1.23, in the treatment. The post test score is 
Effectiveness,

Transcript

1.23 ,

Connected Speech collected after the treatment is given. The score of pre-test, post-test, difference of scores between pre-test and post-test, and the squared score difference contribute to the computation of the effectiveness of the treatment. The scores are illustrated in the table below.

Table 3

Subjects' Score of Connected Speech of Experimental Group

\begin{tabular}{cccccc}
\hline No. & $\begin{array}{c}\text { Subjects' } \\
\text { Code }\end{array}$ & Pre-test & Post-test & D & $\mathbf{D}^{\mathbf{2}}$ \\
\hline 1 & S-1 & 16 & 32 & 16 & 256 \\
\hline 2 & S-2 & 35 & 76 & 41 & 1681 \\
\hline 3 & S-3 & 11 & 29 & 18 & 324 \\
\hline 4 & S-4 & 33 & 74 & 41 & 1681 \\
\hline 5 & S-5 & 38 & 78 & 40 & 1600 \\
\hline 6 & S-6 & 24 & 74 & 50 & 2500 \\
\hline 7 & S-7 & 44 & 83 & 39 & 1521 \\
\hline 8 & S-8 & 14 & 63 & 49 & 2401 \\
\hline 9 & S-9 & 22 & 54 & 32 & 1024 \\
\hline 10 & S-10 & 20 & 68 & 48 & 2304 \\
\hline 11 & S-11 & 35 & 71 & 36 & 1296 \\
\hline 12 & S-12 & 27 & 67 & 40 & 1600 \\
\hline 13 & S-13 & 32 & 65 & 33 & 1089 \\
\hline 14 & S-14 & 37 & 73 & 36 & 1296 \\
\hline 15 & S-15 & 36 & 62 & 26 & 676 \\
\hline 16 & S-16 & 41 & 70 & 29 & 841 \\
\hline 17 & S-17 & 18 & 55 & 37 & 1369 \\
\hline 18 & S-18 & 19 & 76 & 57 & 3249 \\
\hline 19 & S-19 & 24 & 71 & 47 & 2209 \\
\hline 20 & S-20 & 30 & 66 & 36 & 1296 \\
\hline & & $\sum=556$ & $\sum=1.307$ & $\sum=751$ & $\sum=30.213$ \\
\hline & & $\bar{X}=27.80$ & $\bar{X}=65.35$ & & \\
\hline & & & & & \\
\hline
\end{tabular}

The Mean Difference Score of Experimental Group $\left(\mathrm{MD}_{\mathrm{e}}\right)$ of Weak Pronunciation is formulated as $\mathrm{MD}=\mathrm{M}_{2}-\mathrm{M}_{1}$

$$
\begin{aligned}
& \mathrm{MD}_{\mathrm{e}}=65.35-27.80 \\
& \mathrm{MD}_{\mathrm{e}}=37.55
\end{aligned}
$$


The Standard Deviation (SD) of the connected speech performed by the Experimental Group is calculated by applying the formula below:

Effectiveness, Transcript 1.23, Connected

$$
\begin{aligned}
& \mathrm{SD}_{\mathrm{e}}=\sqrt{\frac{30.213-\frac{(751)^{2}}{20}}{20-1}} \\
& \mathrm{SD}_{\mathrm{e}}=\sqrt{\frac{30.213-28.200}{19}} \\
& \mathrm{SD}_{\mathrm{e}}=\sqrt{\frac{2013}{19}}=\sqrt{105} \\
& \mathrm{SD}_{\mathrm{e}}=10.29
\end{aligned}
$$

The effectiveness of using CAPT software Transcript1.23 to improve the

\begin{tabular}{|c|c|c|c|c|c|}
\hline No. & Subjets' Code & Pre-test & Post-test & D & $\mathbf{D}^{2}$ \\
\hline 1 & S-1 & 28 & 42 & 14 & 196 \\
\hline 2 & S-2 & 13 & 35 & 22 & 484 \\
\hline 3 & S-3 & 26 & 59 & 33 & 1089 \\
\hline 4 & S-4 & 33 & 44 & 11 & 121 \\
\hline 5 & S-5 & 23 & 38 & 15 & 225 \\
\hline 6 & S-6 & 11 & 30 & 19 & 361 \\
\hline 7 & S-7 & 24 & 65 & 41 & 1681 \\
\hline 8 & S-8 & 38 & 76 & 38 & 1444 \\
\hline 9 & S-9 & 13 & 30 & 17 & 289 \\
\hline 10 & S-10 & 31 & 50 & 19 & 361 \\
\hline 11 & S-11 & 45 & 59 & 14 & 196 \\
\hline 12 & S-12 & 23 & 39 & 16 & 256 \\
\hline 13 & S-13 & 16 & 33 & 17 & 289 \\
\hline 14 & S-14 & 27 & 34 & 7 & 49 \\
\hline 15 & S-15 & 21 & 30 & 9 & 81 \\
\hline 16 & S-16 & 33 & 42 & 9 & 81 \\
\hline 17 & S-17 & 34 & 46 & 12 & 144 \\
\hline 18 & S-18 & 24 & 31 & 7 & 49 \\
\hline 19 & S-19 & 15 & 26 & 11 & 121 \\
\hline \multirow[t]{3}{*}{20} & $\mathrm{~S}-20$ & 36 & 45 & 9 & 81 \\
\hline & & $\sum=514$ & $\sum=854$ & $\sum=340$ & $\sum=6598$ \\
\hline & & $\bar{X}=25.70$ & $\bar{X}=42.70$ & & \\
\hline
\end{tabular}
students' connected speech is described in the table below.

Table 4

Subjects' Score of Connected Speech of Control Group 
Effectiveness, Transcript

1.23 ,

Connected Speech
The Mean Difference Score of Control Group (MDc) of Connected Speech is calculated as $\mathrm{MD}=\mathrm{M}_{2}-\mathrm{M}_{1}$

$$
\begin{aligned}
\mathrm{MD}_{\mathrm{c}} & =42.70-25.70 \\
\mathrm{MD}_{\mathrm{c}} & =17
\end{aligned}
$$

$$
\begin{aligned}
& \mathrm{SD}_{\mathrm{C}}=\sqrt{\frac{6598-\frac{(340)^{2}}{20}}{20-1}} \\
& \mathrm{SD}_{\mathrm{C}}=\sqrt{\frac{6596-5780}{19}} \\
& \mathrm{SD}_{\mathrm{C}}=\sqrt{42.95} \\
& \mathrm{SD}_{\mathrm{C}}=6.55
\end{aligned}
$$

Pooled Standard Deviation $\left(\mathrm{SD}_{\mathrm{p}}\right)$ is quantified by applying the equation below:

$$
\begin{aligned}
& \mathrm{SD}_{\mathrm{p}}=\frac{10.29+6.55}{2} \\
& \mathrm{SD}_{\mathrm{p}}=\frac{16.84}{2} \\
& \mathrm{SD}_{\mathrm{p}}=8.42
\end{aligned}
$$

The Effect Size (d) of the treatment is calculated by applying the following equation:

$$
\begin{aligned}
& d=\frac{37.55-17.00}{8.42} \\
& d=\frac{20.55}{8.42} \\
& d=2.44
\end{aligned}
$$

As demonstrated in the above computation, the effect size (d) of the treatment is 2.44. By referring to the given criteria, the value is categorized "strong". Based on the score, it can be interpreted that approximately $99 \%$ of the CG are below the average person in the EG after the treatment was given.

\section{Discussion}

The obtained data demonstrates relatively equal scores of both groups' pre-test mean scores. The pre-test mean score of weak form of the EG (42.75) is approximately equal to that of the CG (42.50). This data indicates the subject's lack of prior knowledge about the concerned issues. The subjects obviously fail in reducing less important words 
called function words or grammatical words in their sentence-level pronunciation. In the pre-test, the subjects of both experimental and control groups tend to pronounce all grammatical words in the syntactical construction in strong, cited or full pronunciation. The only function words that most subjects pronounce in weak forms are articles such as the, $a$ and $a n$.

The researcher suspects that the subjects are only familiar with the usually strong pronounced articles mention above. It is evident that most of the subject keep pronouncing the definite article the in weak form /ðə/ although the strong form /ð// is more desirable in the given position. The subjects of the experimental group, for instance, pronounce the function word of definite article the in weak form as ðə '^ðər, ðə Ig'zakt,

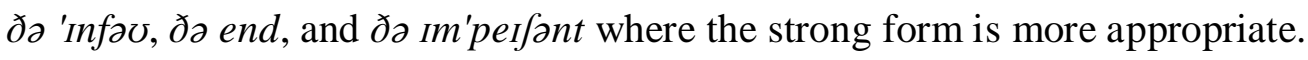

After a treatment is given to the EG, the score of weak form increases from 42.75 in pre-test to 74.81 in post-test. Therefore, it is concluded that the use of CAPT software Transcript1.23 is effective in improving the EG's mean score of weak forms. Compared to the CG post-test mean score, the EG post-test mean score is higher than that of CG. The CG's post-test score increases slightly from the pre-test score 42.50 to 56.75 . This means that the score is still far below the school lowest passing grade for English subject which is usually in range from 65 to 78 depending on the schools. In this case, each school has different standards of lowest passing grade.

The EG's post-test mean score of connected speech is lower than that of the weak forms. From the fact, it can be interpreted that the subject is less familiar with the feature of connected speech in the sentence level pronunciation than the weak pronunciation form. The pre-test mean score of connected speech of both Experimental (27.80) and Control Group (25.70) is equally low. This data reveals the subject's unfamiliarity with the connected speech that actually exists in the natural pronunciation of spoken English.

The previously obtained data proves that the subjects seem to be unfamiliar with the sentence-level pronunciation. This evidence is obtained from the fact that the subjects tend to pronounce separately every single word from another which have been in a syntactical construction. Consequently, the subjects pronounce every single word in a syntactical construction clearly in a strong, cited, rare or full form. This habit makes the participant's pronunciation will always sound unpleasing, unnatural and strange to the native speakers. To the worst, such pronunciation can cause misunderstanding. 
Effectiveness,

Transcript

1.23 ,

Connected

Speech

The application of CAPT software Transcript1.23 is proven to be effective to improve the EG' weak pronunciation and connected speech competence. The mean score of weak pronunciation form of the experimental group raises significantly from 42.75 before treatment to 74.81 after the treatment is given, and so does the connected speech mean score that improves from 27.80 in pre-test to 65.35 in post-test. The control group's achievement score of weak form slightly improves from 42.50 in pre-test to 56.75 in posttest and the connected speech also elevates slightly from 25.70 in pre-test to 42.70 in posttest.

The effect size of applying the software to improve the subject's performance of weak form $(\mathrm{d}=1.99)$ is classified as strong according to Cohen's criteria. This claim is made based on the fact that the size effect is greater than one (1). The effect size score indicates that approximately $97 \%$ of Control Group score of weak pronunciation form is below average person in Experimental Group after the treatment is given. This means that the use of Transcript1.23 as the teaching media to improve the students' weak pronunciation form as one of speaking skills is effective. Thus, both teachers and students can take advantage of this software in the teaching and learning process to improve the natural sentence-level pronunciation which characterises the spoken English.

In conclusion, by referring to Cohen's criteria, the Effect Size (d) of applying the CAPT software Transcript1.23 as a teaching media to improve the subject's realisation of connected speech $(\mathrm{d}=2.44)$ is classified "strong". The size effects score indicates that nearly $99 \%$ of Control Group score of connected speech is below average person in Experimental Group after the treatment is given. This means that the use of the concerned CAPT software as a teaching media to improve students' connected speech is effective.

CAPT software Transcript1.23 uses International Phonetic Alphabet (IPA). Consequently, subjects require sufficient time to familiarise themselves with the phonetic alphabet symbols. The researcher needs to introduce and teach the subjects the correct way to produce the phonemes symbolised by the phonetic alphabets.

Despite the strengths, there might be limitation in this research. This research is categorised as simple from the perspective of the size of the sample. This research involves only 40 subjects consisting of 20 subjects of Experimental Group and the other 
20 subjects of Control Group. The number of subjects is categorised as a small scale research.

From the time viewpoint, this research is a short time research because the process of collecting the data is conducted only in two weeks time. Such a short time might cause the subjects to be less prepared to give their optimal performance.

Effectiveness, Transcript 1.23 , Connected Speech

The collected data ignores the recording repetition for revision that the participants made when recording their voice. This aspect is beyond the researcher's control because the participants make the recording at home. Some students might submit their first record while others might revise their recording repeatedly before submitting it. Another limitation of this research concerns with the unavailability of the CAPT software Transcript1.23 in the free market. Hence, the teachers who would like to obtain the phonetic software can contact the researcher or instead, use other similar software products as the replacement available non-commercially in internet sites.

\section{CONCLUSION}

By referring to the research questions and the results of the data analysis on the subject's pronunciation of weak form and connected speech after the treatment, it is concluded as follows: (1) With the Effect Size (d) score of 1.99 to the Cohen criteria, the use of CAPT software Phonetics1.23 to improve the subject's weak form is effective and the effectiveness is categorized as strong. The effect size score indicates that approximately $97 \%$ of Control Group score of weak pronunciation form is below average person in Experimental Group after the treatment is given. (2) With the Effect Size (d) score of 2.44 according to Cohen criteria, the use of CAPT software Transcript1.23 to improve the subject's connected speech is effective and the effectiveness is categorized "strong". The size effects score indicates that nearly 99\% of Control Group score of connected speech is below average person in Experimental Group after the treatment is given. 
Transcript

1.23

Connected Speech

\section{5}

\section{SUGGESTION}

Based on the research findings, suggestions are presented to the teachers, students, and other researchers. This research scientifically finds the use of CAPT software Transcript1.23 effective to improve the students' pronunciation of weak forms and connected speech. The products are available either commercially or noncommercially to help students achieve satisfying competence in acquiring sentence-level pronunciation which characterises the authentic and natural spoken English.

Students should use the CAPT software Transcript1.23 as a learning media to improve their competence in recognising the sentence-level pronunciation of weak form and connected speech competence that characterises natural spoken English. Researchers who intend to investigate other different effects of using CAPT software Transcript1.23 excluded in this research such as assimilation (of place, manner and voice), elision, neutralisation, breaking, compression, reduction, contraction, intrusion, juncture, and so forth, can utilise this research findings as a reference.

\section{REFERENCES}

AbuSeileek, A. F. (2007). Computer-assisted Pronunciation Instruction as an Effective Way for Teaching Stress. The JALT CALL Journal, 3.

Celce-Murcia, Marianne, Dona M. Brinton, and Janet M.Goodwin. (1996). Teaching Pronunciation: A reference for teachers of English to speakers of other languages. Cambridge: Cambridge University Pres.

Gilakjani, A. P. (2012). The Significance of Pronunciation in English Language Teaching. English Language Teaching, 97.

Lai, C. C. \& Kritsonis, W. A. (2006). The Advantages and Disadvantages of Computer. National Journal for Publishing and Mentoring Doctoral Student Research, 2.

Neri, A., Mich, O., Gerosa, O., \& Giuliani, D. (2008). Computer Assisted Language Learning. London: Routledge

Seyedabadi, S. (2015). Towards Better Teaching of Pronunciation: Review of Literature in the Area. Mediterranean Journal of Social Sciences, 76-77.

Tejeda A. C. T \& Santos N. M. B. (2014). Pronunciation Instruction and Students' Practice to Develop Their Confidence in EFL Oral Skills. Profile, 154.

Tennant, A. (2007). Pronunciation Matters: Sound Reasons for Teaching Pronunciation. SKILLS, 1. 